\title{
Four-year clinical update from a prospective trial of accelerated partial breast intensity-modulated radiotherapy (APBIMRT)
}

\author{
Rachel Y. Lei - Charles E. Leonard - Kathryn T. Howell • Phyllis L. Henkenberns • \\ Timothy K. Johnson • Tracy L. Hobart • Shannon P. Fryman · Jane M. Kercher • \\ Jodi L. Widner · Terese Kaske • Dennis L. Carter
}

Received: 7 May 2013/ Accepted: 22 June 2013/Published online: 4 July 2013

(c) The Author(s) 2013. This article is published with open access at Springerlink.com

\begin{abstract}
This prospective Phase II single-arm study gathered data on the use of intensity-modulated radiotherapy (IMRT) to deliver accelerated partial breast irradiation (APBI). Four-year efficacy, cosmesis, and toxicity results are presented. Between February 2004 and September 2007, 136 consecutive patients with Stage 0/I breast cancer and negative margins $\geq 0.2 \mathrm{~cm}$ were treated on protocol. Patients received 38.5 Gy in 10 equal fractions delivered twice daily. Breast pain and cosmesis were rated by patient, and cosmesis was additionally evaluated by physician per Radiation Therapy Oncology Group (RTOG) criteria. The National Cancer Institute Common Terminology Criteria for Adverse Events (NCI CTCAE v3.0) was used to grade toxicities. 136 patients ( 140 breasts) with median follow-up of 53.1 months (range, 8.9-83.2) were evaluated. Population characteristics included median age of 61.9 years and
\end{abstract}

This trial was registered with clinicaltrials.gov on August 18, 2010 under the identifier NCT 01185145.

R. Y. Lei $(\bowtie) \cdot$ C. E. Leonard · K. T. Howell ·

P. L. Henkenberns - T. K. Johnson - T. L. Hobart - S. P. Fryman Rocky Mountain Cancer Centers, 22 W. Dry Creek Circle, Littleton, CO 80120, USA

e-mail: Rachel.Lei@usoncology.com

C. E. Leonard

e-mail: Charles.Leonard@usoncology.com

R. Y. Lei · S. P. Fryman - D. L. Carter

Rocky Mountain Cancer Center, 1700 S. Potomac Street,

Aurora, CO 80012, USA

J. M. Kercher · J. L. Widner

SurgOne, Greenwood Village, CO, USA

T. Kaske

Sally Jobe Diagnostic Breast Center, Greenwood Village, CO, USA
Tis (13.6\%), T1a (18.6\%), T1b (36.4\%), and T1c $(31.4 \%)$. Kaplan-Meier estimates at 4 years: ipsilateral breast tumor recurrence $0.7 \%$; contralateral breast failure $0 \%$; distant failure $0.9 \%$; overall survival $96.8 \%$; and cancer-specific survival $100 \%$. At last follow-up, patients and physicians rated cosmesis as excellent/good in 88.2 and $90.5 \%$, respectively; patients rated breast pain as none/mild in $97.0 \%$. Other observations included edema $(1.4 \%)$, telangiectasia $(3.6 \%)$, five cases of grade 1 radiation recall $(3.6 \%)$, and two cases of rib fractures $(1.4 \%)$. This analysis represents the largest cohort and longest follow-up of APBI utilizing IMRT reported to date. Four-year results continue to demonstrate excellent local control, survival, cosmetic results, and toxicity profile.

Keywords Accelerated partial breast irradiation - Breast cancer - Breast-conserving therapy - Intensity-modulated radiotherapy $\cdot$ Adjuvant radiotherapy

\section{Introduction}

Breast-conserving therapy (BCT) of lumpectomy followed by radiotherapy has disease-free and overall survivals comparable to those of mastectomy, for ductal carcinoma in situ (DCIS) and early stage invasive breast cancer [1-4]. The 5-7 weeks required for the current standard of care whole breast irradiation (WBI) can be a significant deterrent for patients who would otherwise be good candidates for BCT [5-7]. Studies have investigated delivering a biologically equivalent radiation dose to the involved region over a shortened time frame [8-44]. The rationale for irradiating only a partial breast volume, including observations that a majority of ipsilateral breast tumor recurrences (IBTR) developed at or in the area of the tumor bed, has been 
thoroughly elaborated elsewhere [8, 9]. This alternative treatment approach is commonly known as accelerated partial breast irradiation (APBI).

Various techniques for APBI delivery have been explored over the past decade, including interstitial (multicatheter) brachytherapy [10-15], single-entry brachytherapy using intracavitary devices such as MammoSite [16-20], external beam radiotherapy (EBRT) utilizing photons [21-37] or protons [38,39], and intraoperative radiotherapy (IORT) delivered as a single fraction at the time of definitive surgery [40-43]. EBRT, specifically EBRT utilizing 3-dimensional conformal planning (3D-CRT), has gained popularity due to its noninvasive nature, decreased procedural trauma to the breast, ease of adoption for most radiation treatment facilities, and its suitability for most cases (in terms of tumor location and breast volume) [8, 9, 44]. APBI using EBRT is associated with a lower risk of seroma formation and infection than APBI delivered by brachytherapy [44]. Compared to brachytherapy and IORT techniques, 3D-CRT offers the best target coverage and the most homogenous dose distribution (i.e., minimizing "hot spots," the amount of breast tissue receiving radiation doses markedly exceeding the prescription dose); potential drawbacks of 3D-CRT include radiation exposure to a larger volume of the uninvolved ipsilateral breast, heart, and lung tissue (to account for tumor motion and setup variability), leading to a higher integral dose (total energy deposited in the patient) $[8,44]$.

While 3D-CRT relies on physical wedges (also known as blocks) to reduce the dose delivered by each treatment beam to adjacent healthy tissue, intensity-modulated radiotherapy (IMRT), a technique that might be considered the next generation of 3D-CRT, enables rapid re-blocking while the patient is being treated, thus allowing the radiation oncologist to vary the size and intensity of treatment beams to deliver spatially nonuniform doses that result in a homogenous dose distribution at the target site. The high precision and customizability afforded by IMRT has led to superior clinical outcomes and reduced toxicities in prostate (and other organs) irradiation compared to 3D-CRT [45-53]; accordingly, IMRT has been adopted as a new standard of care in prostate, head and neck, and central nervous system irradiation. Several studies utilizing IMRT to deliver WBI (including randomized, nonrandomized, and single-arm prospective studies compared to historical controls) have demonstrated dosimetric advantages of IMRT over 3D-CRT with accompanying decreases in incidence, duration, and severity of toxicities such as dermatitis, pruritus, moist desquamation, edema (both acute and chronic), and hyperpigmentation [48-53].

Despite the potential advantages of IMRT over 3DCRT, relatively few groups have investigated the use of IMRT to deliver APBI. Among the pending large randomized clinical trials directly comparing WBI to adjuvant APBI (including GEC-ESTRO interstitial brachytherapy, IMPORT Low, NSABP B-39/RTOG 0413, and RAPID), only the British IMPORT Low study makes use of IMRT. Since one key advantage of BCT over mastectomy is the potential preservation of the appearance and sensation of the breast, recent institutional reports of adverse cosmesis and toxicity from APBI using 3D-CRT $[30,32]$ have been received with concern. Early 3D-CRT toxicities from B-39 were reassuringly low [27], leading many to suppose that the adverse outcomes reported were due to institutional practices or small sample size. However, the Canadian-based RAPID study has now reported interim toxicity and cosmesis results, showing that APBI delivered with 3D-CRT was associated with worse cosmetic outcomes and late radiation changes at 3 years compared to WBI [29].

This prospective, hypothesis-generating Phase II singlearm study gathered dosimetric data and clinical outcomes of APBI delivered with IMRT (APBIMRT). We previously compared 56 APBIMRT plans from this trial to 3D-CRT plans following B-39 dose constraints retrospectively constructed on the same cases [34]; IMRT improved normal tissue sparing in the ipsilateral breast without compromising treatment target coverage. This report presents the 4-year disease control, cosmesis, and toxicity outcomes for the first 140 breasts treated on this Phase II study at our institutions.

\section{Materials and methods}

\section{Patient population}

Between February 2004 and September 2007, 150 consecutive patients with Stage 0/I breast cancer were prospectively enrolled on an Institutional Review Boardapproved study of APBIMRT. Subsequently, 14 patients were not treated with APBIMRT: 2 due to patient choice, 1 due to insurance concerns, and 11 due to technical ineligibility. Of the 11 ineligible patients, 1 was ineligible because the lumpectomy cavity could not be visualized on planning scans for contouring, and the remaining either had lumpectomy cavities deemed too large for APBI or the cavities were so medial in location that the dose constraints for the heart or the contralateral breast could not be met. The remaining 136 patients ( 4 with bilateral disease) were treated at 6 facilities in Colorado, USA. Internal retrospective review showed that $2 / 136$ did not meet all eligibility criteria but were treated according to protocol and therefore included in this analysis.

The eligibility requirements were initially age $\geq 45$ years, Stage T1N0M0 (as defined by AJCC Cancer Staging Manual, 6th edition), and negative margins 
$\geq 2 \mathrm{~mm}$ after final surgery (re-excision permitted). The protocol was later amended to include patients $\geq 40$ years old and pure DCIS.

\section{IMRT planning and treatment}

Treatment technique, target volume and normal tissue contouring, and dose constraints have been previously reported in detail [34] and summarized here. The first 8 patients were treated to the prescribed dose of $34 \mathrm{~Gy}$, and the remaining patients to $38.5 \mathrm{~Gy}$. Patients were treated while supine in 10 equal fractions delivered twice daily (with 6-h interfractional minimum) over 5 consecutive days; 1 patient received treatment over 6 days and 2 over 9 days due to unplanned linear accelerator maintenance or inclement weather. The clinical target volume (CTV) was initially defined as the lumpectomy cavity $+2 \mathrm{~cm}$ for the patients treated to $34 \mathrm{~Gy}$, then decreased to lumpectomy cavity $+1 \mathrm{~cm}$ when the prescribed dose was increased to $38.5 \mathrm{~Gy}$; the planning target volume (PTV) was defined as $\mathrm{CTV}+1 \mathrm{~cm}$. No respiratory gating or active breathing control was used. The CTV was at least $0.5 \mathrm{~cm}$ from the chest wall and the skin surface. The PTV/ipsilateral breast volume ratio was generally limited to $\leq 20 \%$. Plans were optimized so $\geq 95 \%$ of the PTV received $\geq 95 \%$ of the prescribed dose. Heart exposure was limited to $\leq 5 \%$ organ volume receiving $>5 \%$ of the prescribed dose. Ipsilateral lung exposure was initially limited to $\leq 15 \%$ receiving $>30 \%$ of the prescribed dose $(n=8)$, then reduced to $\leq 10 \%$ receiving $>30 \%$ of the prescribed dose $(n=123)$, and eventually to $\leq 10 \%$ receiving $>20 \%$ of the prescribed dose for the remaining cases in this series after we gained more experience with image-guided radiotherapy (IGRT). IGRT utilizing nonmigrating fiducial markers [35] was adopted after more than 100 cases and used to treat 32 breasts in this cohort. For breasts treated without IGRT, treatment was set up to skin tattoos and verified with orthogonal pair MV imaging, approved prior to the first treatment and confirmed intermittently throughout the treatment course. APBIMRT was completed prior to any chemotherapy.

\section{Cosmesis and toxicities}

Cosmesis and toxicities were evaluated 4-6 weeks after treatment completion, then every 3-4 months for 2 years; protocol was later amended to encourage yearly follow-up beyond 2 years. Patients were asked to rate breast pain as none, mild, moderate or severe, and cosmesis as excellent, good, fair or poor without further instructions. Cosmesis was additionally evaluated by physician per RTOG criteria; (presumed) surgical effects on cosmesis were not excluded. The National Cancer Institute Common Terminology
Criteria for Adverse Events (CTCAE v3.0) was used to grade toxicities. Rib fractures were confirmed by $2 \mathrm{D}$ plain films.

Statistical methods

Time intervals were calculated from completion of APBI unless noted otherwise. IBTRs were defined as the recurrence of cancer in the treated breast. Treatment failures were dated to pathologic diagnosis of recurrence. Univariate analysis was performed with the two-sample $t$ test (age and volumetric data were analyzed as continuous variables) and the $\chi^{2}$ test for independent observations and the paired $t$ test for repeated measures. Equality of variance was verified with the $F$ test to insure applicability of twosample $t$ tests. Multivariate analysis was performed with repeated measures ANOVA. Statistical significance was defined as $p \leq 0.05$ with $\alpha=0.05, p$ values were onesided (following standard $\chi^{2}$ and $F$ distributions).

\section{Results}

Patients

136 patients (140 breasts) were evaluated. The median follow-up from APBI completion (for recurrence and survival) was 53.1 months (8.9-83.2).

\section{MRI scanning}

Bilateral MRI to rule out occult disease was not required but was performed for the majority of patients. All 19 cases with DCIS (100\%), 5 with invasive lobular (100\%), 3 with mixed invasive ductal and lobular histologies (100\%), and 83 with invasive ductal histology with accompanying DCIS component (80.7\%) had MRI scanning.

\section{Patient and treatment-related characteristics}

Patient characteristics (Table 1) were generally favorable, with median age of 61.9 years, median Tumor size of $0.95 \mathrm{~cm}, 76.4 \%$ with a closest margin $>0.5 \mathrm{~cm}$, and $90.7 \%$ estrogen receptor (ER) positive. Of note, over half of the cases are classified as either "unsuitable" for APBI outside of a clinical trial ( $n=17,16 / 17$ cases were diagnosed at $<50$ years old, $2 / 17$ cases of microscopically multifocal DCIS spanning $>3 \mathrm{~cm}$ ) or "cautionary" ( $n=66,47 / 66$ cases were diagnosed at ages 50-59, 11/66 ER negative) according to the APBI consensus guidelines published in 2009 by the American Society for Radiation Oncology (ASTRO) [44]. 
Table 1 Patient characteristics

\begin{tabular}{|c|c|c|c|}
\hline Characteristic & $\begin{array}{l}\text { All patients } \\
(n=140 \text { breasts })\end{array}$ & $\begin{array}{l}\text { Stage } \mathrm{I} \\
(n=121 \text { breasts })\end{array}$ & $\begin{array}{l}\text { Stage } 0 \\
(n=19 \text { breasts })\end{array}$ \\
\hline \multicolumn{4}{|l|}{ Age at diagnosis $(y)$} \\
\hline Median (range) & $61.9\left(37.2-96.8^{\mathrm{a}}\right)$ & $61.6\left(37.2-96.8^{\mathrm{a}}\right)$ & $62.4(41.9-72.8)$ \\
\hline \multicolumn{4}{|l|}{ Menopausal status at study entry $(n)$} \\
\hline Pre/Perimenopausal & $26(18.6 \%)$ & $22(18.2 \%)$ & $4(21.0 \%)$ \\
\hline Postmenopausal & $114(81.4 \%)$ & $99(81.8 \%)$ & $15(79.0 \%)$ \\
\hline \multicolumn{4}{|l|}{ Primary histology $(n)$} \\
\hline Ductal carcinoma in situ & $19(13.6 \%)$ & & 19 \\
\hline Invasive ductal carcinoma & $116(82.9 \%)$ & $116(95.9 \%)$ & \\
\hline Invasive lobular carcinoma & $5(3.6 \%)$ & $5(4.1 \%)$ & \\
\hline Tumor grade $(n)$ & & Histologic grade & Nuclear grade \\
\hline Low & & $61(50.4 \%)$ & $5(26.3 \%)$ \\
\hline Intermediate & & $40(33.1 \%)$ & $7(36.85 \%)$ \\
\hline High & & $16(13.2 \%)$ & $7(36.85 \%)$ \\
\hline Unavailable & & $4(3.3 \%)$ & \\
\hline \multicolumn{4}{|l|}{ Size of invasive tumors $(\mathrm{cm})$} \\
\hline Median (Range) & & $0.95(0.1-2)$ & \\
\hline \multicolumn{4}{|l|}{ Presence of central necrosis $(n)$} \\
\hline Yes & & & $10(52.6 \%)$ \\
\hline No & & & $9(47.4 \%)$ \\
\hline \multicolumn{4}{|l|}{ Total span of DCIS (cm) } \\
\hline Median (Range) & & & $0.5(0.1-4)$ \\
\hline \multicolumn{4}{|l|}{ Multifocal DCIS $(n)$} \\
\hline Yes & & & $5(26.3 \%)$ \\
\hline No & & & $14(73.7 \%)$ \\
\hline \multicolumn{4}{|l|}{ Margin size $(\mathrm{cm})$} \\
\hline Median (Range) & $0.8\left(0-2.1^{\mathrm{a}}\right)$ & $0.9\left(0-2.1^{\mathrm{a}}\right)$ & $0.8(0.2-1.5)$ \\
\hline \multicolumn{4}{|l|}{ Estrogen receptor status $(n)$} \\
\hline Positive & $127(90.7 \%)$ & $111(91.7 \%)$ & $16(84.2 \%)$ \\
\hline Negative & $13(9.3 \%)$ & $10(8.3 \%)$ & $3(15.8 \%)$ \\
\hline \multicolumn{4}{|l|}{ HER2/neu status $(n)$} \\
\hline Positive & $14(10.0 \%)$ & $13(10.0 \%)$ & $1(5.2 \%)$ \\
\hline Negative & $102(72.9 \%)$ & $102(84.3 \%)$ & $0(0 \%)$ \\
\hline Unknown & $24(17.1 \%)$ & $6(5.0 \%)$ & $18(94.7 \%)$ \\
\hline ER negative and HER2 negative $(n)$ & $7(5.0 \%)$ & $7(5.8 \%)$ & $0(0 \%)$ \\
\hline \multicolumn{4}{|l|}{ Sentinel nodes sampled $(n)$} \\
\hline Median (Range) & $2(0-11)$ & $2(1-11)$ & $0(0-3)$ \\
\hline \multicolumn{4}{|l|}{ Total nodes sampled $(n)$} \\
\hline Median (Range) & $2(0-14)$ & $3(1-14)$ & $0(0-7)$ \\
\hline \multicolumn{4}{|l|}{ T stage $(n)$} \\
\hline Tis & $19(13.6 \%)$ & & $19(100 \%)$ \\
\hline T1mic & $6(4.3 \%)$ & $6(5.0 \%)$ & \\
\hline T1a & $20(14.3 \%)$ & $20(16.5 \%)$ & \\
\hline $\mathrm{T} 1 \mathrm{~b}$ & $51(36.4 \%)$ & $51(42.1 \%)$ & \\
\hline $\mathrm{T} 1 \mathrm{c}$ & $44(31.4 \%)$ & $44(36.4 \%)$ & \\
\hline \multicolumn{4}{|l|}{$\mathrm{N}$ stage $(n)$} \\
\hline No & $136(97.1 \%)$ & $117(96.7 \%)$ & $19(100 \%)$ \\
\hline $\mathrm{N} 0(\mathrm{i}+)$ & $4(2.9 \%)$ & $4(3.3 \%)$ & $0(0 \%)$ \\
\hline Bilateral breast MRI prior to enrollment $(n)$ & $117(83.6 \%)$ & $98(80.1 \%)$ & $19(100 \%)$ \\
\hline
\end{tabular}


Table 1 continued

\begin{tabular}{|c|c|c|c|}
\hline Characteristic & $\begin{array}{l}\text { All patients } \\
(n=140 \text { breasts })\end{array}$ & $\begin{array}{l}\text { Stage I } \\
(n=121 \text { breasts })\end{array}$ & $\begin{array}{l}\text { Stage } 0 \\
(n=19 \text { breasts })\end{array}$ \\
\hline \multicolumn{4}{|l|}{ ASTRO APBI Consensus [44] Category $(n)$} \\
\hline Suitable & $57(40.7 \%)$ & $57(47.1 \%)$ & $0(0 \%)$ \\
\hline Cautionary & $67(47.9 \%)$ & $51(42.1 \%)$ & $16(84.2 \%)$ \\
\hline Unsuitable & $16(11.4 \%)$ & $13(10.7 \%)$ & $3(15.8 \%)$ \\
\hline \multicolumn{4}{|l|}{ Adjuvant Treatment $(n)$} \\
\hline RT only & $24(17.1 \%)$ & $15(12.4 \%)$ & $9(47.4 \%)$ \\
\hline RT + endocrine therapy (no chemotherapy) & $97(69.3 \%)$ & $87(71.9 \%)$ & $10(52.6 \%)$ \\
\hline RT + chemotherapy (no endocrine therapy) & $8(5.7 \%)$ & $8(6.6 \%)$ & \\
\hline $\mathrm{RT}+$ chemotherapy + endocrine therapy & $11(7.9 \%)$ & $11(9.1 \%)$ & \\
\hline \multicolumn{4}{|c|}{ Time from end of RT to beginning of chemotherapy (month) } \\
\hline Median (Range) & & $0.4(0.1-2.4)$ & \\
\hline \multicolumn{4}{|c|}{ Time from end of RT to beginning of endocrine therapy (month) } \\
\hline Median (Range) & $0.5(-1.9$ to 4.6$)$ & $0.5(-1.9$ to 4.6$)$ & $0(-0.9$ to 2.0$)$ \\
\hline
\end{tabular}

${ }^{a}$ As mentioned in the Materials/Methods section, 2 patients that did not meet all eligibility criteria but were treated on protocol were included in the analysis and account for the age and margin size values listed in this table outside the range specified by the protocol

Table 2 Cosmesis and pain outcomes

\begin{tabular}{|c|c|c|c|c|c|c|}
\hline \multirow[t]{2}{*}{ Visit $^{a}$} & \multicolumn{2}{|c|}{ Patient-rated cosmesis } & \multicolumn{2}{|c|}{ Physician-rated cosmesis } & \multicolumn{2}{|c|}{ Patient-rated pain } \\
\hline & $n^{\mathrm{b}}$ & Excellent/good & $n^{\mathrm{b}}$ & Excellent/good & $n^{\mathrm{b}}$ & None/mild \\
\hline 12 months & 121 & $118(97.5 \%)$ & 120 & $118(98.3 \%)$ & 130 & $127(97.7 \%)$ \\
\hline 24 months & 100 & $93(93.0 \%)$ & 101 & $98(97.1 \%)$ & 113 & $110(97.7 \%)$ \\
\hline 36 months & 77 & $67(87.0 \%)$ & 80 & $72(90.00 \%)$ & 91 & $87(95.6 \%)$ \\
\hline 48 months & 72 & $62(86.1 \%)$ & 74 & $66(89.2 \%)$ & 83 & $82(98.8 \%)$ \\
\hline 60 months & 39 & $35(90.8 \%)$ & 41 & $36(87.8 \%)$ & 46 & $44(95.7 \%)$ \\
\hline
\end{tabular}

${ }^{a}$ From end of RT, closest follow-up within \pm 180 days to time point specified

b Breasts with evaluated cosmesis/pain

Treatment efficacy

Kaplan-Meier estimates of efficacy at 4 years: IBTR $0.7 \%$; contralateral breast failure $0 \%$; distant failure $0.9 \%$; overall survival $96.8 \%$; and cancer-specific survival $100 \%$. The one patient with subsequent IBTR was originally diagnosed at age 44 with a $0.2 \mathrm{~cm}$ high-grade DCIS tumor with comedonecrosis, margins $\geq 0.5 \mathrm{~cm}$, and ER and PR negative (HER2/neu not tested). The IBTR (diagnosed $\sim 14$ months after treatment completion) was also high-grade DCIS, located at $\geq 3.7 \mathrm{~cm}$ from the original tumor by one author's (T. K.) review of diagnostic imaging, and verified to be outside the treatment volume (referencing the fiducial markers placed for IGRT), and therefore an "elsewhere" failure [14, 54]. No true recurrence/marginal miss or ipsilateral nodal failures were observed.
Cosmetic and pain results

Table 2 and Fig. 1 present the patient- and physician-rated cosmesis as well as patient-rated pain in this study population over time.

Patient- and physician-rated cosmesis outcomes assessed at the same time points were categorized into excellent/ good and fair/poor and analyzed for agreement. There was $97 \%$ agreement $(n=116)$ at 12 months and $92.2 \%$ $(n=77)$ at 24 months.

\section{Univariate analysis}

Univariate analysis showed no relationship between age at diagnosis, re-excision, use of IGRT, ipsilateral breast volume (IB), PTV, and PTV/IB ratio to patient- or MD-rated cosmesis or patient-reported pain at last follow-up. The 
Fig. 1 Cosmesis and pain outcomes, legend: cosmesis: marbled gray poor, striped gray fair, solid light gray good, solid dark gray excellent, pain: striped gray moderate, solid light gray mild, solid dark gray none, excellent/good cosmesis: dotted line with diamond markers patient-rated, solid line with square markers physicianrated
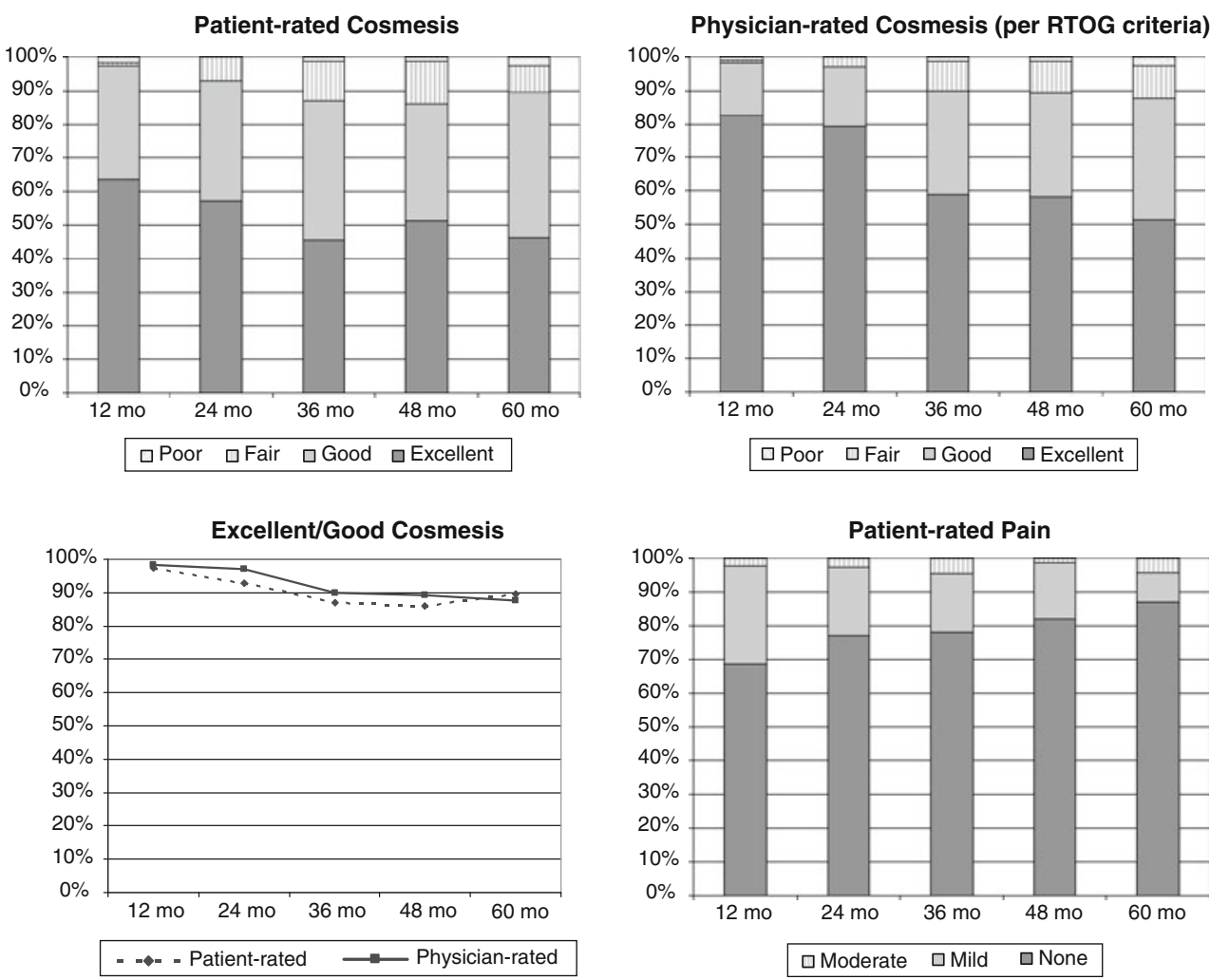

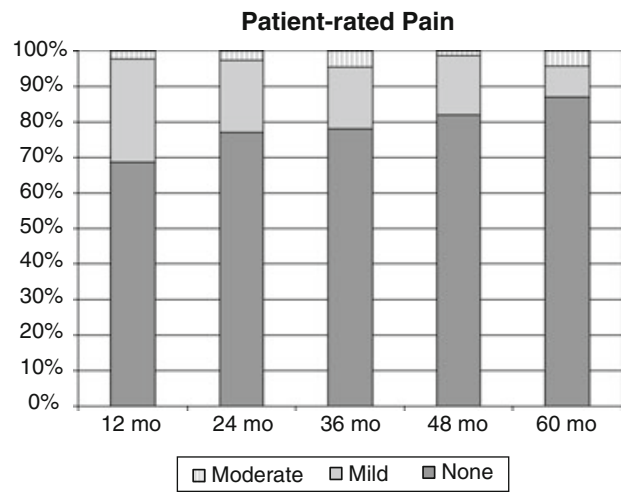

Table 3 Treatment toxicities (highest grade reported for each breast)

\begin{tabular}{lllll}
\hline & Grade 0 & Grade 1 & Grade 2 & Grade 3 \\
\hline $\begin{array}{c}\text { Breast edema } \\
(n=138)\end{array}$ & $12(90.6 \%)$ & $11(8.0 \%)$ & $2(1.4 \%)$ & $0(0 \%)$ \\
$\begin{array}{c}\text { Telangiectasia } \\
(n=138)\end{array}$ & $129(93.5 \%)$ & $7(5.1 \%)$ & $2(1.4 \%)$ & $0(0 \%)$ \\
$\begin{array}{c}\text { Radiation recall } \\
(n=139)\end{array}$ & $134(96.4 \%)$ & $5(3.6 \%)$ & $0(0 \%)$ & $0(0 \%)$ \\
$\begin{array}{c}\text { Rib fracture } \\
(n=139)\end{array}$ & $137(98.6 \%)$ & $0(0 \%)$ & $2(1.4 \%)$ & $0(0 \%)$ \\
\hline
\end{tabular}

lack of relationship between PTV and pain contrasts our prior report [37]. However, the current analysis corroborates the statistically significant relationship between the volume of the chest wall receiving $>35$ Gy and patientreported pain as previously discussed (results not shown).

Patients who reported moderate/severe pain at any point during follow-up were proportionally more likely to report fair/poor cosmesis at last follow-up $(p=0.008)$.

Patients who received endocrine therapy were proportionally less likely to report pain at last follow-up $(p=0.003)$. Patients who received endocrine therapy exhibited a non-significant trend toward reporting excellent/good cosmesis at last follow-up $(p=0.068)$.

\section{Multivariate analysis}

Multivariate analysis including time from RT and use of endocrine therapy showed no relationship between either factor and patient-reported cosmesis or pain. There was a statistically significant decrease in physician-rated cosmesis over time $(p=0.003)$. This decrease remained significant when the model accounted for variations in endocrine therapy, re-excision, and age, and appeared to stabilize after 36 months from RT (Fig. 1; paired $t$ test confirmed loss of statistically significant difference between physician-rated cosmesis at 36 and 48 months). Due to the small number of physician-evaluated cosmesis available at 60 months for comparison at this current time $(n=29)$, this apparent stabilization requires future confirmation.

Treatment-related toxicities

Table 3 details the highest grade of toxicities reported for each breast at any time following APBI. No grade $2+$ acute skin toxicities and no heart or lung toxicities (of any grade) were observed. At last follow-up, toxicities reported were mild $(1.4 \%)$ edema, and mild $(2.2 \%)$ or moderate $(1.4 \%)$ telangiectasia. The adverse event "radiation recall" corresponded to dermatitis associated with chemotherapy 
administered after completion of radiation, and was graded according to CTCAE v3.0.

\section{Discussion}

This report is an update to previous publications [34-37] and represents the largest cohort and longest follow-up of APBIMRT reported to date. Four-year results continue to demonstrate excellent local control, survival, cosmetic results, and toxicity profile and support the continued use and study of this technique. Table 4 offers an exploratory comparison between this study and representative adjuvant APBI studies that utilized brachytherapy, 3D-CRT, or IMRT techniques.

Comparison of clinical outcomes to other APBI reports

As EBRT techniques for APBI delivery have become more widely used, multiple institutions and cooperative groups have published varying rates of late toxicity (Table 4). One of the explanations offered by the RAPID study team for their 3D-CRT APBI cosmesis results was lack of conformality, i.e., the breast volume receiving high radiation doses did not correspond precisely enough to the treatment target volume. As we previously reported, in comparison to 3D-CRT, IMRT significantly increased conformality and correspondingly improved normal ipsilateral tissue sparing; the volume of ipsilateral lung and heart irradiated was small with both techniques but decreased with IMRT [36]. The clinical implications of these findings were further delineated by a later investigation demonstrating correlation between patient-reported pain after APBIMRT and chest wall volume receiving $>35$ Gy [37]. These findings led us to hypothesize that improved normal tissue sparing offered by IMRT may also improve clinical outcomes, such as pain or cosmesis. Accordingly, in October 2007 (after the entire patient series analyzed in this report had completed treatment), our institutional guidelines for APBI using IGRT were amended to further reduce the PTV. Leonard et al. [30] suggests that in the setting of larger radiation doses over shorter time frames (hypofractionation), small differences in prescribed dose and dose distribution may result in dramatic differences in normal tissue complication. Table 5 lists some key technical differences between representative external beam APBI studies, including the sizes of margin added to the lumpectomy cavity to form the PTV.

Both the Tufts and the University of Michigan studies have reported associations between dose-volume data and adverse clinical outcomes [30, 32]. Leonard et al. [30] demonstrated statistically significant associations between the percentage of breast volume receiving at least $100 \%$
(V100) and $50 \%$ (V50) of the prescribed dose to subcutaneous fibrosis $(p=0.001$ and 0.01$)$, cosmesis $(p=0.02$ and 0.04 ), and grade $2+$ toxicity ( $p=0.009$ and 0.003$)$. Jagsi et al. [32] also reported a significant association between V100 and V50 to cosmesis ( $p=0.02$ and 0.002). These findings suggest that it is not enough to simply compare outcomes from different ABPI techniques (i.e., 3D-CRT vs. IMRT, EBRT vs. brachytherapy); subtle dosimetric considerations, e.g., differences between V100 and V50 reported by the 2 IMRT studies in Table 5, and other factors, such as immobilization techniques, timing of radiotherapy, the use of other adjuvant therapies, methodological differences in cosmesis assessment, statistical anomalies associated with small sample sizes and/or short follow-up, etc., may also contribute to variability in cosmesis and late toxicities.

The IBTR rate and clinical outcomes reported by this study are comparable to outcomes of other APBI series (Table 4). One theoretical concern regarding the improved tissue sparing offered by IMRT is a potential increase in marginal failures, but marginal failures were not observed in this study population. Whether IMRT offers clinical advantages such as less severe late toxicities over other APBI techniques still requires testing in a randomized setting.

MRI scanning in patient series

The role of MRI scanning in the management of breast cancer is highly controversial and variable throughout the world. Some studies have demonstrated that MRI identified ipsilateral and/or contralateral occult disease and changed APBI eligibility in $8.8 \%$ [55] to $12.9 \%$ [56] of prospectively screened clinical candidates. MRI scanning to confirm suitability for breast conservation was not required by this study but is commonly utilized by breast surgeons in our region. A detailed analysis for (or against) the routine use of MRI in determining APBI eligibility, including whether it is cost-effective, and whether it has a clinically significant impact on long term APBI outcomes, is outside the scope of this paper. Nevertheless, it may be worth noting that this study is the only one among published EBRT APBI studies [10, 21-37] to report extensive use of breast MRI scanning in the diagnostic workup of the patient series. The effect of MRI on patient selection could partially account for the low IBTR rate $(0.7 \%)$ we observed.

\section{Patient selection for APBI}

APBI has gained popularity not only for its convenience to patients, but also with the increasing recognition that in cancer care, the more expansive treatment approach is not 


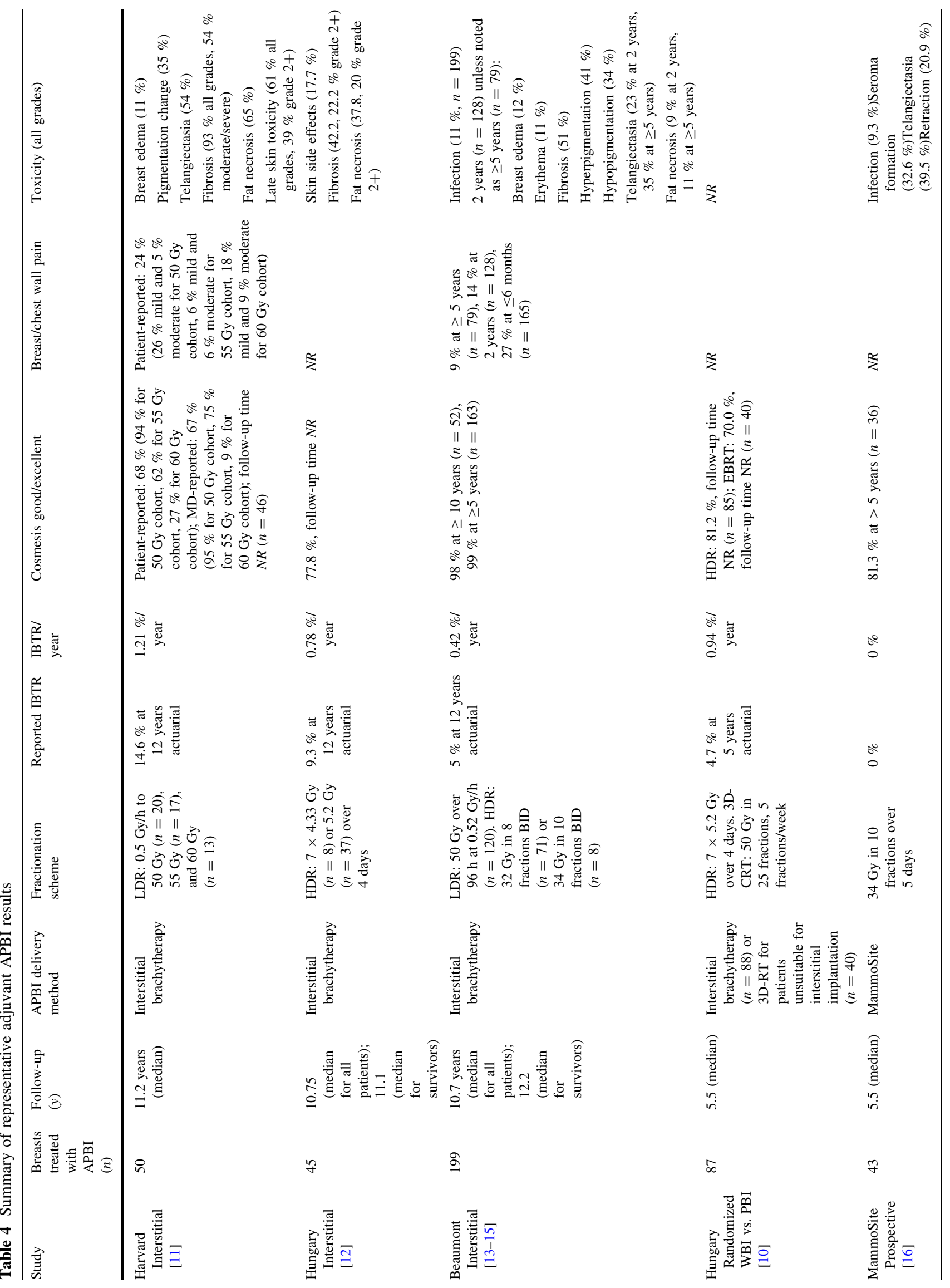




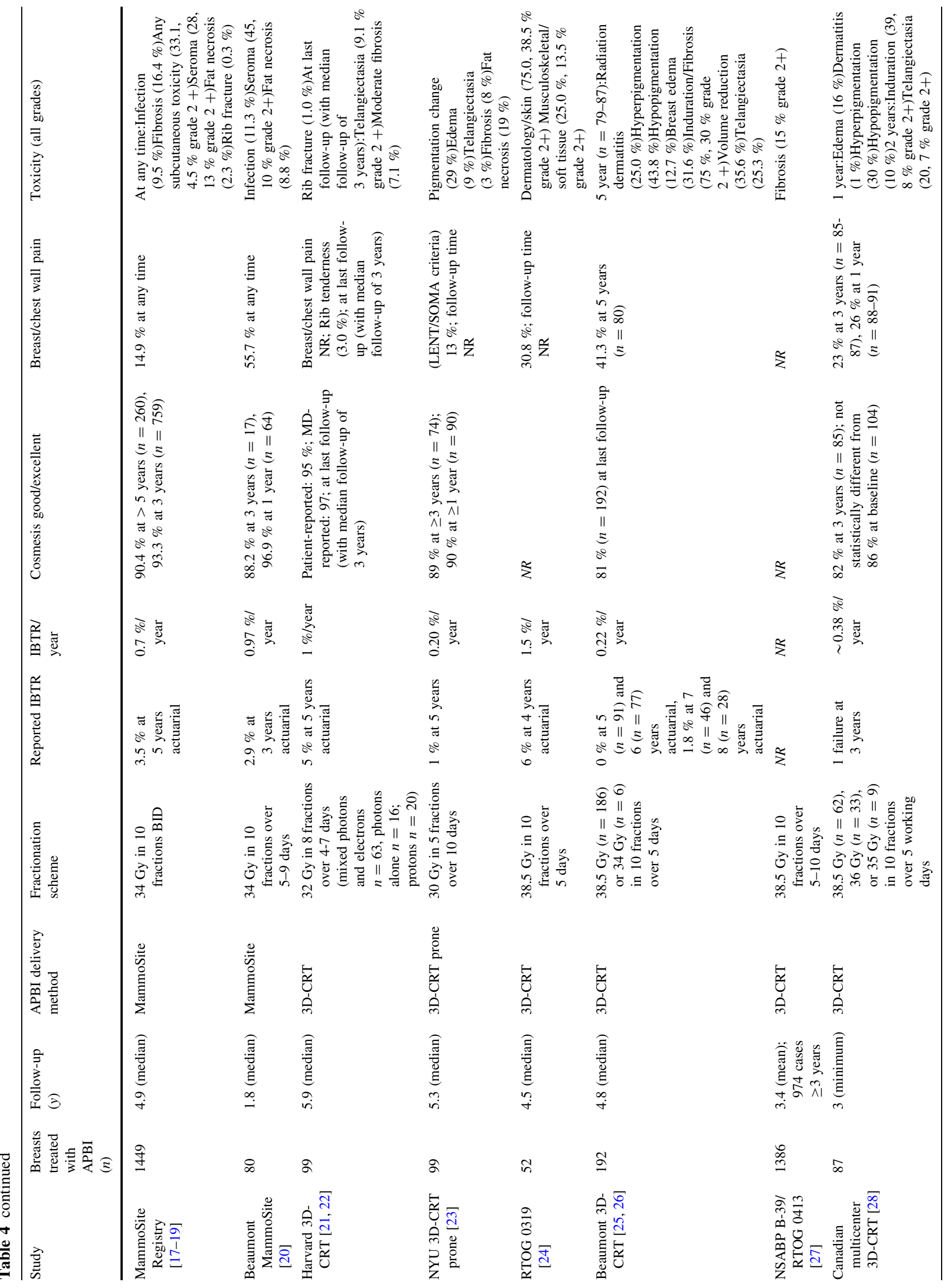




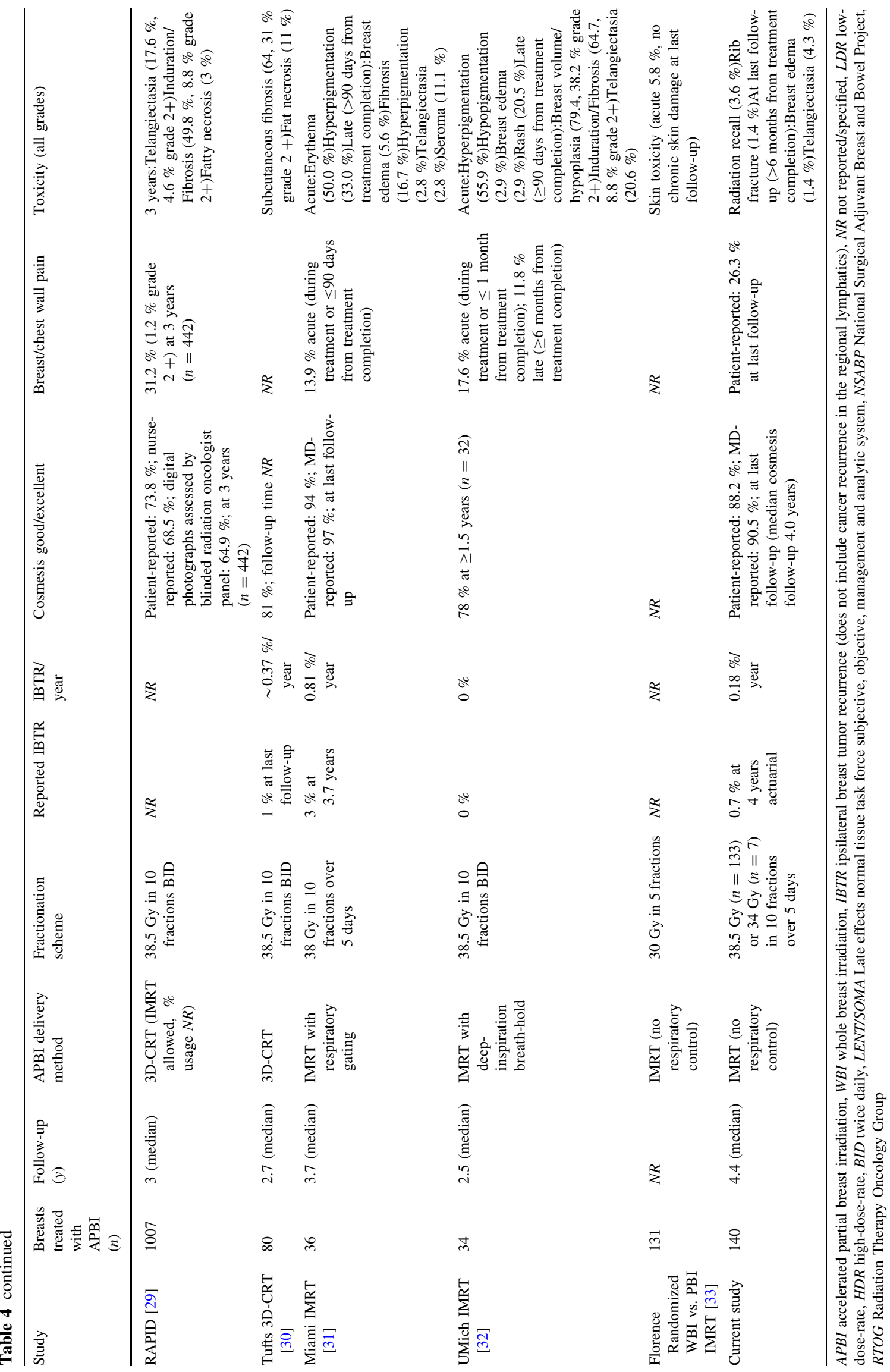




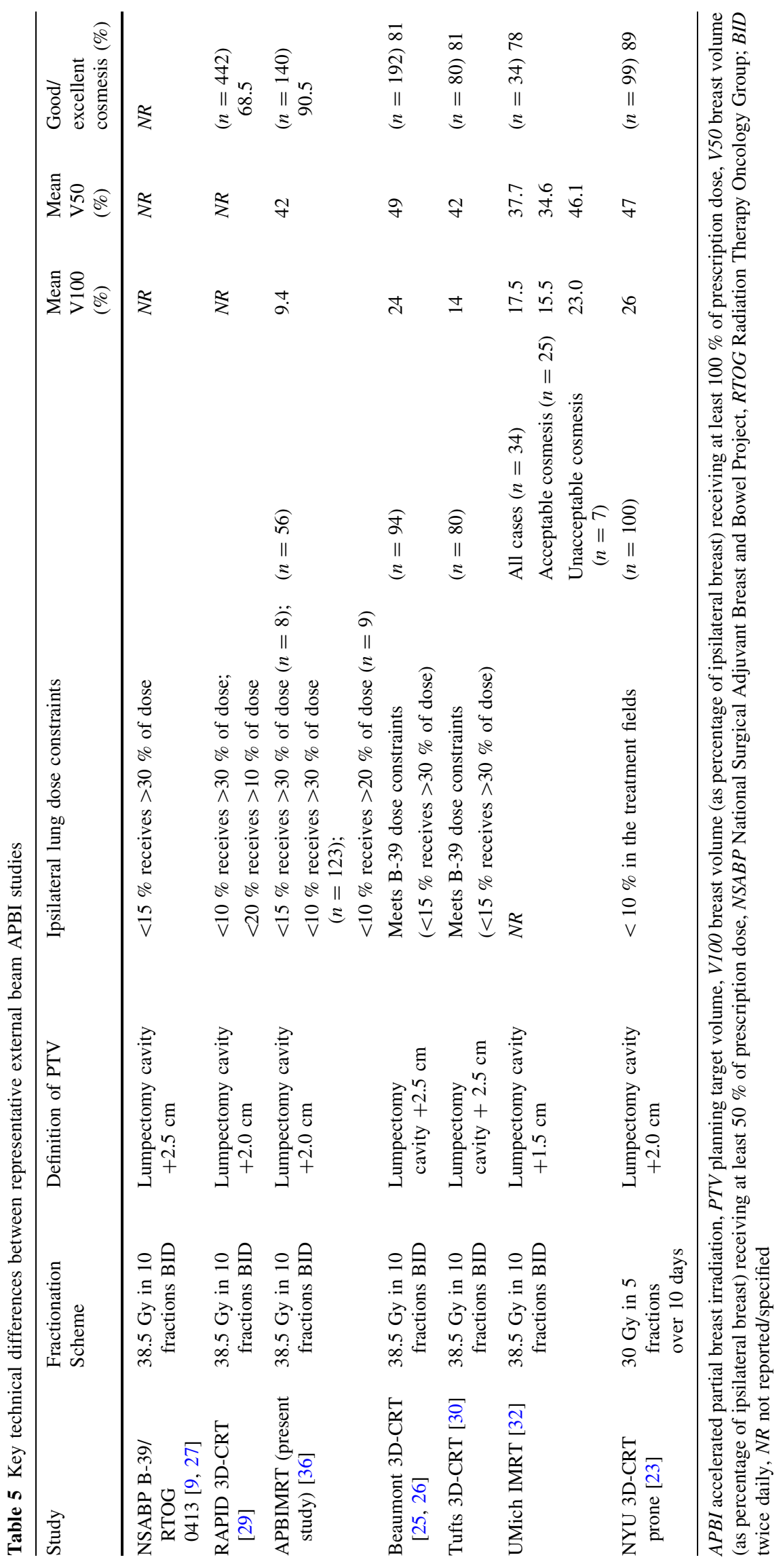


always better. APBI has always-conceptually as well as in published data-relied on proper selection, typically of cases with clinicopathologic factors associated with low risk for recurrence, and encompass patients whose treatment options may include not only conventional WBI but observation as well (although it should be noted that a subgroup of patients in which RT does not reduce locoregional recurrence has yet to be identified [57, 58]). The optimal patient population for APBI remains controversial, as evidenced by the different sets of guidelines offered by ASTRO, The Groupe Européen de Curiethérapie and European Society for Therapeutic Radiology and Oncology (GEC-ESTRO), the American Society of Breast Surgeons, and the American Brachytherapy Society, as well as the numerous retrospective studies questioning the merits of these guidelines [44, 59-63].

The results reported here provide early confirmation of the importance of proper patient selection and also suggest that some patients deemed "cautionary" or even "unsuitable" may ultimately be appropriate for APBI. Although the ASTRO consensus guidelines established a population of patients "suitable" for APBI outside a clinical study [44], we continue to treat $\sim 98 \%$ of our institutional APBI cases on study and closely monitor the outcomes. Of note, this study is one of a few APBI studies utilizing EBRT to include synchronous (or metachronous) bilateral disease. Since the protocol limited the dose to the contralateral breast to less than $3 \%$ of the prescribed dose, there was minimal dose overlap between the 2 breasts, and therefore bilateral treatment with APBIMRT was technically feasible.

The debate over the clinical role of APBI is not likely to be resolved until results are available from the large randomized clinical trials. Nevertheless, the favorable local control and late toxicity profiles detailed in this report continue to support APBIMRT as a promising treatment option worthy of further investigation. With the increasing attention to cost-effective health resource allocation, the greater cost of IMRT (relative to the 3D-CRT technique) may partially account for the lack of trials investigating the use of IMRT to deliver APBI. A careful comparison of outcomes from patients treated with APBI using 3D-CRT and IMRT - that specifically addresses whether the dosimetric advantages afforded by IMRT translates into meaningful clinical benefit-is a prerequisite for any meaningful cost-effectiveness analysis between 3D-CRT and IMRT. It should be noted, however, that APBIMRT has been shown to cost substantially less than single-catheter APBI techniques [64], and still remains attractive compared to conventional WBI over 6 weeks, or even hypofractionated WBI over 4 weeks, in terms of cost to payers [64], impact on departmental resources [65], and presumably overall societal cost, even more so when decreased transportation costs and time off from work are taken into account.
We previously demonstrated that IMRT provides excellent treatment target coverage while generally reducing the volume of ipsilateral breast, chest wall, lung, and heart exposed to high doses [36], and that increased pain correlated with larger chest wall and overall volumes receiving $>75 \%$ of the prescribed dose [37]. This report provides a significant update with a greater number of patients and longer follow-up that is especially relevant in the current context of discrepant cosmesis and toxicity reported by various APBI studies utilizing EBRT. Our currently enrolling Phase III randomized study will include a direct comparison of clinical outcomes of patients treated with APBI-using 3D-CRT and IMRT techniques.

\section{Disclosures None.}

Funding source Department of Radiation Oncology, Rocky Mountain Cancer Centers.

Open Access This article is distributed under the terms of the Creative Commons Attribution Noncommercial License which permits any noncommercial use, distribution, and reproduction in any medium, provided the original author(s) and the source are credited.

\section{References}

1. Veronesi U, Cascinelli N, Mariani L, Greco M, Saccozzi R, Luini A, Aquilar M, Marubini E (2002) Twenty-year follow-up of a randomized study comparing breast-conserving surgery with radical mastectomy for early breast cancer. N Engl J Med 347:1227-1232

2. Fisher B, Anderson S, Bryant J, Margolese RG, Deutsch M, Fisher ER, Jeong JH, Wolmark N (2002) Twenty-year follow-up of a randomized trial comparing total mastectomy, lumpectomy, and lumpectomy plus irradiation for the treatment of invasive breast cancer. N Eng J Med 347:1233-1241

3. EORTC Breast Cancer Cooperative Group, EORTC Radiotherapy Group, Bijker N, Meijnen P, Peterse JL, Bogaerts J, Van Hoorebeeck I, Julien JP, Gennaro M, Rouanet P, Avril A, Fentiman IS, Bartelink H, Rutgers EJ (2006) Breast-conserving treatment with or without radiotherapy in ductal carcinomain situ: ten-year results of European Organisation for Research and Treatment of Cancer randomized phase III trial 10853-a study by the EORTC Breast Cancer Cooperative Group and EORTC Radiotherapy Group. J Clin Oncol 24:3381-3387

4. Solin LJ, Fourquet A, Vicini FA, Taylor M, Olivotto IA, Haffty B, Strom EA, Pierce LJ, Marks LB, Bartelink H, McNeese MD, Jhingran A, Wai E, Bihjker N, Campana F, Hwang WT (2005) Long-term outcome after breast-conservation treatment with radiation for mammographically detected ductal carcinoma in situ of the breast. Cancer 103:1137-1146

5. Gilligan MA, Kneusel RT, Hoffmann RG, Greer AL, Nattinger AB (2002) Persistent differences in sociodemographic determinants of breast conserving treatment despite overall increased adoption. Med Care 40:181-189

6. Nattinger AB, Kneusel RT, Hoffmann RG, Gilligan MA (2001) Relationship of distance from a radiotherapy facility and initial breast cancer treatment. J Natl Cancer Inst 93:1344-1346 
7. Nattinger AB, Hoffmann RG, Kneusel RT, Schapira MM (2000) Relation between appropriateness of primary therapy for earlystage breast carcinoma and increased use of breast-conserving surgery. Lancet 356:1148-1153

8. Offersen BV, Overgaard M, Kroman N, Overgaard J (2009) Accelerated partial breast irradiation as part of breast conserving therapy of early breast carcinoma: a systematic review. Radiother Oncol 90:1-13

9. NSABP B-39/RTOG 0413 protocol. https://members.nsabp.pitt. edu/B39_Protocol.pdf. Accessed 9 Jan 2013

10. Polgár C, Fodor J, Major T, Németh G, Lövey K, Orosz Z, Sulyok Z, Takácsi-Nagy Z, Kásler M (2007) Breast-conserving treatment with partial or whole breast irradiation for low-risk invasive breast carcinoma: 5-year results of a randomized trial. Int J Radiat Oncol Biol Phys 69:694-702

11. Hattangadi JA, Powell SN, MacDonald SM, Mauceri T, Ancukiewicz M, Freer P, Lawenda B, Alm El-Din MA, Gadd MA, Smith BL, Taghian AG (2012) Accelerated partial breast irradiation with low-dose-rate interstitial implant brachytherapy after wide local excision: 12-year outcomes from a prospective trial. Int J Radiat Oncol Biol Phys 83:791-800

12. Polgár C, Major T, Fodor J, Sulyok Z, Somogyi A, Lövey K, Németh G, Kásler M (2010) Accelerated partial-breast irradiation using high-dose-rate interstitial brachytherapy: 12-year update of a prospective clinical study. Radiother Oncol 94:274-279

13. Shah C, Antonucci JV, Wilkinson JB, Wallace M, Ghilezan M, Chen P, Lewis K, Mitchell C, Vicini F (2011) Twelve-year clinical outcomes and patterns of failure with accelerated partial breast irradiation versus whole-breast irradiation: results of a matched-pair analysis. Radiother Oncol 100:210-214

14. Vicini FA, Antonucci JV, Wallace M, Gilbert S, Goldstein NS, Kestin L, Chen P, Kunzman J, Boike T, Benitez P, Martinez A (2007) Long-term efficacy and patterns of failure after accelerated partial breast irradiation: a molecular assay-based clonality evaluation. Int J Radiat Oncol Biol Phys 68:341-346

15. Chen PY, Vicini FA, Benitez P, Kestin LL, Wallace M, Mitchell C, Pettinga J, Martinez AA (2006) Long-term cosmetic results and toxicity after accelerated partial-breast irradiation: a method of radiation delivery by interstitial brachytherapy for the treatment of early-stage breast carcinoma. Cancer 106:991-999

16. Benitez PR, Keisch ME, Vicini F, Stolier A, Scroggins T, Walker A, White J, Hedberg P, Hebert M, Arthur D, Zannis V, Quiet C, Streeter O, Silverstein M (2007) Five-year results: the initial clinical trial of MammoSite balloon brachytherapy for partial breast irradiation in early-stage breast cancer. Am J Surg 194:456-462

17. Beitsch PD, Wilkinson JB, Vicini FA, Haffty B, Fine R, Whitworth P, Kuerer H, Zannis V, Lyden M (2012) Tumor bed control with balloon-based accelerated partial breast irradiation: incidence of true recurrences versus elsewhere failures in the American Society of Breast Surgery MammoSite Registry Trial. Ann Surg Oncol 19:3165-3170

18. Khan AJ, Arthur D, Vicini F, Beitsch P, Kuerer H, Goyal S, Lyden M, Haffty BG (2012) Six-year analysis of treatmentrelated toxicities in patients treated with accelerated partial breast irradiation on the American Society of Breast Surgeons MammoSite Breast Brachytherapy registry trial. Ann Surg Oncol 19:1477-1483

19. Vicini FA, Keisch M, Shah C, Goyal S, Khan AJ, Beitsch PD, Lyden M, Haffty BG (2012) Factors associated with optimal long-term cosmetic results in patients treated with accelerated partial breast irradiation using balloon-based brachytherapy. Int $\mathbf{J}$ Radiat Oncol Biol Phys 83:512-518

20. Chao KK, Vicini FA, Wallace M, Mitchell C, Chen P, Ghilezan M, Gilbert S, Kunzman J, Benitez P, Martinez A (2007) Analysis of treatment efficacy, cosmesis, and toxicity using the MammoSite breast brachytherapy catheter to deliver accelerated partial- breast irradiation: The William Beaumont Hospital experience. Int J Radiat Oncol Biol Phys 69:32-40

21. Pashtan IM, Recht A, Ancukiewicz M, Brachtel E, Abi-Raad RF, D'Alessandro HA, Levy A, Wo JY, Hirsch AE, Kachnic LA, Goldberg S, Specht M, Gadd M, Smith BL, Powell SN, Taghian AG (2012) External beam accelerated partial-breast irradiation using 32 Gy in 8 twice-daily fractions: 5 year results of a prospective study. Int J Radiat Oncol Phys 84:e271-e277

22. Taghian AG, Alm El-Din M, Smith BL, Ancukiewicz M, MacDonald SS, Katz A, Specht M, Hirsch A, Powell SN, Recht A (2008) Interim results of a phase I/II trial of 3D-conformal external beam accelerated partial breast irradiation in patients with early breast cancer [Abstract]. Presented at the American Society for Radiation Oncology 50th Annual Meeting, September 21-25, Boston. MA. Int J Radiat Oncol Phys 72(Suppl):S4

23. Formenti SC, Hsu H, Fenton-Kerimian M, Roses D, Guth A, Jozsef G, Goldberg JD, Dewyngaert JK (2012) Prone accelerated partial breast irradiation after breast-conserving surgery: five-year results of 100 patients. Int J Radiat Oncol Biol Phys 84:606-611

24. Vicini F, Winter K, Wong J, Pass H, Rabinovitch R, Chafe S, Arthur D, Petersen I, White J, McCormick B (2010) Initial efficacy results of RTOG 0319: Three-dimensional conformal radiation therapy (3D-CRT) confined to the region of the lumpectomy cavity for stage I/II breast carcinoma. Int J Radiat Oncol Biol Phys 77:1120-1127

25. Shah C, Wilkinson JB, Lanni T, Jawad M, Wobb J, Fowler A, Wallace M, Chen P, Grillis IS, Vincini F (2012) Five-year outcome and toxicities using 3-dimensional conformal external beam radiation therapy to deliver accelerated partial breast irradiation. Clin Breast Cancer 12:259-263

26. Chen PY, Wallace M, Mitchell C, Grillis I, Kestin L, Fowler A, Martinez A, Vicini F (2010) Four-year efficacy, cosmesis, and toxicity using three-dimensional conformal external beam radiation therapy to deliver accelerated partial breast irradiation. Int $\mathrm{J}$ Radiat Oncol Biol Phys 76:991-997

27. Julian TB, Constantino JP, Vicini FA, White JR, Winter A, Arthur DW, Kuske RR, Rabinovitch R, Curran WJ Jr, Wolmark N (2011) Early toxicity results with 3D conformal external beam therapy (CEBT) from the NSABP B-39/RTOG 0413 accelerated partial breast irradiation (APBI) trial [Abstract]. Presented at the American Society for Radiation Oncology 53rd Annual Meeting, October 2-6, Miami Beach, FL. Int J Radiat Oncol Phys 81(Suppl):S7

28. Berrang TS, Olivotto I, Kim DH, Nichol A, Cho BC, Mohamed IG, Parhar T, Wright JR, Truong P, Tyldesley S, Sussman J, Wai E, Whelan T (2011) Three-year outcomes of a Canadian multicenter study of accelerated partial breast irradiation using conformal radiation therapy. Int J Radiat Oncol Biol Phys 81:1220-1227

29. Whelan TJ, Olivotto I, Parpia S, Berrang T, Kim D, Kong I, Truong P, Cochrane B, Julian J, RAPID Trial Investigators (2013) Interim toxicity results from RAPID: a randomized trial of accelerated partial breast irradiation (APBI) using 3D conformal external beam radiation therapy (3D CRT) [Abstract]. Presented at the American Society for Radiation Oncology 54th Annual Meeting, October 28-31, 2012, Boston, MA. Int J Radiat Oncol Phys 85:21-22

30. Leonard KL, Hepel JT, Hiatt JR, Dipetrillo TA, Price LL, Wazer DE (2013) The effect of dose-volume parameters and interfraction interval on cosmetic outcome and toxicity after 3-dimensional conformal accelerated partial breast irradiation. Int $\mathrm{J}$ Radiat Oncol Phys 85:623-629

31. Lewin AA, Derhagopian R, Saigal K, Panoff JE, Abitbol A, Wieczorek DJ, Mishra V, Reis I, Ferrell A, Moreno L, Takita C (2012) Accelerated partial breast irradiation is safe and effective using intensity-modulated radiation therapy in selected earlystage breast cancer. Int J Radiat Oncol Phys 82:2104-2110 
32. Jagsi R, Ben-David MA, Moran JM, Marsh RB, Griffith KA, Hayman JA, Pierce LJ (2010) Unacceptable cosmesis in a protocol investigating intensity-modulated radiotherapy with active breathing control for accelerated partial-breast irradiation. Int $\mathbf{J}$ Radiat Oncol Biol Phys 76:71-78

33. Livi L, Buonamici FB, Simontacchi G, Scotti V, Fambrini M, Compagnucci A, Paiar F, Scoccianti S, Pallotta S, Detti B, Agresti B, Talamonti C, Mangoni M, Bianchi S, Cataliotti L, Marrazo L, Bucciolini M, Biti G (2010) Accelerated partial breast irradiation with IMRT: new technical approach and interim analysis of acute toxicity in a phase III randomized trial. Int $\mathbf{J}$ Radiat Oncol Biol Phys 77:509-515

34. Leonard CE, Carter DL, Kercher J et al (2007) Prospective trial of accelerated partial breast intensity-modulated radiotherapy. Int J Radiat Oncol Biol Phys 67:1291-1298

35. Leonard CE, Tallhamer M, Johnson T, Hunter K, Howell K, Kercher J, Widener J, Kaske T, Paul D, Sedlacek S, Carter (2010) Clinical experience with image-guided radiotherapy in an accelerated partial breast intensity-modulated radiotherapy protocol. Int J Radiat Oncol Biol Phys 76:234-528

36. Rusthoven KE, Carter DL, Howell K, Kercher JM, Henkenberns P, Hunter KL, Leonard CE (2008) Accelerated partial-breast intensity-modulated radiotherapy results in improved dose distribution when compared with three-dimensional treatmentplanning techniques. Int J Radiat Oncol Biol Phys 70:296-302

37. Reeder R, Carter DL, Howell K, Henkenberns P, Tallhamer M, Johnson T, Kercher J, Widner J, Kaske T, Paul D, Sedlacek S, Leonard CE (2009) Predictors for clinical outcomes after accelerated partial breast intensity-modulated radiotherapy. Int $\mathrm{J}$ Radiat Oncol Biol Phys 74:92-97

38. Kozak KR, Smith BL, Adams J, Kornmehl E, Katz A, Gadd M, Specht M, Hughes K, Gioioso V, Lu HM, Braaten K, Recht A, Powell SN, DeLaney TF, Taghian AG (2006) Accelerated partialbreast irradiation using proton beams: initial clinical experience. Int J Radiat Oncol Biol Phys 66:691-698

39. Wang $X$, Amos RA, Zhang X, Taddei PJ, Woodward WA, Hoffman KE, Yu TK, Tereffe W, Oh J, Perkins GH, Salehpour M, Zhang SX, Sun TL, Gillin M, Buchholz TA, Strom EA (2011) External-beam accelerated partial breast irradiation using multiple proton beam configurations. Int J Radiat Oncol Biol Phys 80:1464-1472

40. Leonardi MC, Ivaldi GB, Santoro L, Lazzari R, Ferrari A, Morra A, Caldarella P, Burgoa L, Bassi FD, Sangalli C, Rotmensz N, Luini A, Veronesi U, Orecchia R (2012) Long-term side effects and cosmetic outcome in a pool of breast cancer patients treated with intraoperative radiotherapy with electrons as sole treatment. Tumori 98:324-330

41. Vaidya JS, Wenz F, Bulsara M, Joseph D, Tobias JS, Keshtgar M, Flyger H, Massarut S, Alvarado M, Saunders C, Eiermann W, Metaxas M, Sperk E, Sutterlin M, Brown D, Esserman L, Roncadin M, Thompson A, Dewar JA, Holtveg H, Pigorsch S, Falzon M, Harris E, Matthews A, Brew-Graves C, Potyka I, Corica T, Williams NR, Baum M (2012) Targeted intraoperative radiotherapy for early breast cancer: TARGIT-A Trial-updated analysis of local recurrence and first analysis of survival [Abstract]. Presented at the 35th annual San Antonio breast cancer symposium, December 4-8, San Antonio, TX. Cancer Research 72(Suppl):100s-101s

42. Beal K, Sacchini V, Zelefsky M, Rogers KH, McCormick B (2012) Five year update on intraoperative radiation therapy for breast cancer [Abstract]. Presented at the American Society for Radiation Oncology 53rd Annual Meeting, October 2-6, Miami Beach, FL. Int J Radiat Oncol Phys 81(Suppl):S241-S242

43. Vanderwalde NA, Jones EL, Kimple RJ, Moore DT, KlauberDemore N, Sartor CI, Ollila DW (2013) Phase 2 study of preexcision single-dose intraoperative radiation therapy for early- stage breast cancers: six-year update with application of the ASTRO accelerated partial breast irradiation consensus statement criteria. Cancer 119:1736-1743

44. Smith BD, Arthur DW, Buchholz TA, Haffty BG, Hahn CA, Hardenbergh PH, Julian TB, Marks LB, Todor DA, Vicini FA, Whelan TJ, White J, Wo JY, Harris JR (2009) Accelerated partial breast irradiation consensus statement from the American Society for Radiation Oncology (ASTRO). Int J Radiat Oncol Biol Phys 74:987-1001

45. Zelefsky MJ, Levin EJ, Hunt M, Yamada Y, Shippy AM, Jackson A, Amols HI (2008) Incidence of late rectal and urinary toxicities after three-dimensional conformal radiotherapy and intensitymodulated radiotherapy for localized prostate cancer. Int J Radiat Oncol Biol Phys 70:1124-1129

46. Sharma NK, Li T, Chen DY, Pollack A, Horwitz EM, Buyyounouski MK (2011) Intensity-modulated radiotherapy reduces gastrointestinal toxicity in patients treated with androgen deprivation therapy for prostate cancer. Int J Radiat Oncol Biol Phys 80:437-444

47. Sheets NC, Goldin GH, Meyer AM, Wu Y, Chang Y, Stürmer T, Holmes JA, Reeve BB, Godley PA, Carpenter WR, Chen RC (2012) Intensity-modulated radiation therapy, proton therapy, or conformal radiation therapy and morbidity and disease control in localized prostate cancer. JAMA 307:1611-1620

48. Pignol JP, Olivotto I, Rakovitch E, Gardner S, Sixel K, Beckham W, Vu TT, Truong P, Ackerman I, Paszat L (2008) A multicenter randomized trial of breast intensity-modulated radiation therapy to reduce acute radiation dermatitis. $\mathrm{J}$ Clin Oncol 26: 2085-2092

49. Barnett GC, Wilkinson J, Moody AM, Wilson CB, Sharma R, Klager S, Hoole AC, Twyman N, Burnet NG, Coles CE (2009) A randomised controlled trial of forward-planned radiotherapy (IMRT) for early breast cancer: baseline characteristics and dosimetry results. Radiother Oncol 92:34-41

50. Hardee ME, Raza S, Becker SJ, Jozsef G, Lymberis SC, Hochman T, Goldberg JD, DeWyngaert KJ, Formenti SC (2012) Prone hypofractionated whole-breast radiotherapy without a boost to the tumor bed: comparable toxicity of IMRT versus a 3D conformal technique. Int J Radiat Oncol Biol Phys 82:e415-e423

51. Freedman GM, Li T, Nicolaou N, Chen Y, Ma CC, Anderson PR (2009) Breast intensity-modulated radiation therapy reduces time spent with acute dermatitis for women of all breast sizes during radiation. Int J Radiat Oncol Biol Phys 74:689-694

52. McDonald MW, Godette KD, Butker EK, Davis LW, Johnstone PA (2008) Long-term outcomes of IMRT for breast cancer: a singleinstitution cohort analysis. Int J Radiat Oncol Biol Phys 72:1031-1040

53. Harsolia A, Kestin L, Grills I, Wallace M, Jolly S, Jones C, Lala M, Martinez A, Schell S, Vicini FA (2007) Intensity-modulated radiotherapy results in significant decrease in clinical toxicities compared with conventional wedge-based breast radiotherapy. Int J Radiat Oncol Biol Phys 68:1375-1380

54. Recht A, Silver B, Schnitt S, Connolly J, Hellman S, Harris JR (1985) Breast relapse following primary radiation therapy for early breast cancer. I. Classification, frequency and salvage. Int J Radiat Oncol Biol Phys 11:1271-1276

55. Kühr M, Wolfgarten M, Stölzle M, Leutner C, Holler T, Schrading S, Kuhn W, Braun M (2011) Potential impact of preoperative magnetic resonance imaging of the breast on patient selection for accelerated partial breast irradiation. Int $\mathrm{J}$ Radiat Oncol Biol Phys 81:e541-e546

56. Dorn PL, Al-Hallaq HA, Haq F, Goldberg M, Abe H, Hasan Y, Chmura SL (2013) A prospective study of the utility of magnetic resonance imaging in determining candidacy for partial breast irradiation. Int J Radiat Oncol Biol Phys 85:615-622

57. Darby S, McGale P, Correa C, Taylor C, Arriagada R, Clarke M, Cutter D, Davies C, Ewertz M, Godwin J, Gray R, Pierce L, 
Whelan T, Wang Y, Peto R, Early Breast Cancer Trialists' Collaborative Group (2011) Effect of radiotherapy after breast-conserving surgery on 10-year recurrence and 15-year breast cancer death: meta-analysis of individual patient data for 10,801 women in 17 randomised trials. Lancet 378:1707-1716

58. Mannino M, Yarnold JR (2009) Local relapse rates are falling after breast conserving surgery and systemic therapy for early breast cancer: can radiotherapy ever be safely withheld? Radiother Oncol 90:14-22

59. Polgár C, Van Limbergen E, Pötter R, Kovács G, Polo A, Lyczek J, Hildebrandt G, Niehoff P, Guinot JL, Guedea F, Johansson B, Ott OJ, Major T, Strnad V, GEC-ESTRO breast cancer working group (2010) Patient selection for accelerated partial-breast irradiation (APBI) after breast-conserving surgery: recommendations of the Groupe Europeen de Curietherapie-European Society for Therapeutic Radiology and Oncology (GEC-ESTRO) breast cancer working group based on clinical evidence (2009). Radiother Oncol 94:264-273

60. Board of Directors ASoBS (2011) Consenus statement for accelerated partial breast irradiation. https://www.breastsurgeons. org/statements/PDF_Statements/APBI.pdf. Accessed 14 June 2013

61. Breast Brachytherapy Task Group, ABS (2007) ABS Breast Brachytherapy Task Group. http://www.americanbrachytherapy. org/guidelines/abs_breast_brachytherapy_taskgroup.pdf. Accessed 14 June 2013

62. Vicini F, Arthur D, Wazer D, Chen P, Mitchell C, Wallace M, Kestin L, Ye H (2011) Limitations of the American Society of Therapeutic Radiology and Oncology Consensus Panel guidelines on the use of accelerated partial breast irradiation. Int $\mathbf{J}$ Radiat Oncol Biol Phys 79:977-984

63. Shaitelman SF, Vicini FA, Beitsch P, Haffty B, Keisch M, Lyden M (2010) Five-year outcome of patients classified using the American Society for Radiation Oncology consensus statement guidelines for the application of accelerated partial breast irradiation: an analysis of patients treated on the American Society of Breast Surgeons MammoSite Registry Trial. Cancer 116: 4677-4685

64. Amin N, Konski AA (2013) Is hypofractionation the solution? The financial implications of breast cancer treatments. Oncology vol 27. April 15, 2013. http://www.cancernetwork.com/breastcancer/content/article/10165/2137308. Accessed 12 June 2013

65. Dwyer P, Hickey B, Burmeister E, Burmeister B (2010) Hypofractionated whole-breast radiotherapy: impact on departmental waiting times and cost. J Med Imaging Radiat Oncol 54:229-234 